\title{
THE FORMATION OF THE INDIAN ENTREPRENEURIAL COMMUNITY IN JAPAN IN THE END OF 19TH - EARLY 20TH CENTURIES
}

\author{
Varvara Sergeevna Firsova \\ Candidate for a Degree, Department of Ethnography of South and Southwest Asia, \\ Peter the Great's Museum of Anthropology and Ethnography (Kunstkamera), RAS, \\ Junior Researcher, Library of RAS, Department of Literature on Asian and African Countries \\ varvarafirsova@yandex.ru \\ Universitetskaya Emb., 3, 199034 Saint Petersburg, Russian Federation
}

\begin{abstract}
The present article is based on Western, Japanese and field-work materials of the author who describes the main stages of formation of the Indian entrepreneurial diaspora in Japan in the period from the late 19th century until the beginning of the World War II. Indian entrepreneurs, being the representatives of trade and usury communities, Sindhis and Parsis in particular, started to arrive here in 1870s under British protection. Their main occupation was the export of Japanese textile which was the main export item of Japan in the mentioned period. Indians maintained the export of the textile goods, silk and cotton, in different countries all over the world through their strong entrepreneurial networks. The majority of Indian firms in Japan were Sindhis firms, and Sindhis network was especially prominent. Indian firms especially prospered in 1920-1930s, when their share of Japanese textile export constituted about $70 \%$. Thanks to strong ethnic loyalties, Indians in Japan could not only prosper but also successfully adapt to closed Japanese society. The article considers the pattern of settlement of Indians in Japan, and emphasizes two stages of Indian community formation in the pre-War period. The first one lasted from 1870s till 1923 year, when the community was formed basically in Yokohama. And the second stage after Great Kanto Earthquake lasted from 1923 till 1939, when it was constituted mainly in Kobe, which in present days remains the centre of Indian entrepreneurial community in Japan.
\end{abstract}

Key words: Indian diaspora, Japan, entrepreneurial diaspora, Sindhis community, ethnic entrepreneurial network.

УДК 94(520).03+94(54).035+338(091)

Дата поступления статьи: 07.02.2016

ББК 63.3(5Япо)+63.3(5Инд)+65.9(2)09

\section{ФОРМИРОВАНИЕ ИНДИЙСКОЙ ПРЕДПРИНИМАТЕЛЬСКОЙ ОБЩИНЫ В ЯПОНИИ С КОНЦА ХІХ - В ПЕРВОЙ ПОЛОВИНЕ ХХ ВЕКА}

\author{
Варвара Сергеевна Фирсова \\ Соискатель отдела этнографии Южной и Юго-Западной Азии, \\ Музей антропологии и этнографии им. Петра Великого РАН (Кунсткамера), \\ младший научный сотрудник Библиотеки РАН, Отдел литературы стран Азии и Африки (ОЛСАА) \\ varvarafirsova@yandex.ru \\ Университетская набережная, д. 3, 199034 г. Санкт-Петербург, Российская Федерация
}

Аннотация. В данной статье на основе западных, японских, а также полевых материалов автора статьи рассматриваются основные этапы формирования индийской предпринимательской общины в Японии в период с 1870-х гг. до начала Второй мировой войны. Индийские предприниматели, представители торговоростовщических каст, в частности парсы и синдхи, пользуясь покровительством Великобритании, начали приезжать сюда для ведения бизнеса, главным образом торговли текстилем. Благодаря налаженной предпринимательской сети, индийцы экспортировали японский текстиль в различные страны по всему миру. Особенно отмечается успех синдхских фирм, составлявших большинство индийских фирм в Японии в указанный период. Благодаря сильной этнической солидарности между представителями, индийцы смогли не только 
добиться коммерческого успеха (в довоенный период на долю индийцев приходилось около 70 \% экспорта японского шелка), но и успешно адаптироваться к жизни в Японии. Отмечены два этапа формирования индийской общины и особенности их расселения в двух городах Японии. С 1870-х гг. - по 1923 г. община главным образом формировалась в Икогаме, а после Великого Токийского землетрясения - в Кобэ, который и в настоящее время продолжает оставаться основным центром концентрации индийской предпринимательской общины.

Ключевые слова: индийская диаспора, Япония, предпринимательская диаспора, синдхи, этническая предпринимательская сеть.

Довольно много исследовательских работ посвящено роли иностранцев во время проведения важнейших социальных, экономических и культурных преобразований Японии во второй половине XIX в., получивших название «Революция Мэйдзи» $[1 ; 4]$. Большинство работ ограничиваются описанием жизни и деятельности европейцев и американцев в Японии того времени. Однако гораздо хуже известно о том, что уже с 1870-х гг. в Японию для ведения бизнеса начали приезжать индийские предприниматели, представители индийских торгово-ростовщических каст. Необходимо отметить, что деятельность индийской общины не всегда бывает полно и достоверно отражена в исторических документах и официальной статистике, что является одной из причин немногочисленности до недавнего времени работ, посвященных индийцам в Японии.

Цель данной статьи заключается в рассмотрении на основе западных и японских источников первых этапов формирования индийской предпринимательской общины до начала Второй мировой войны, когда отмечался особый расцвет индийских фирм в Японии, а также вклад индийской предпринимательской сети в развитие довоенной японской экономики.

\section{Первый этап. \\ Формирование общины в г. Иокогаме}

В 1854 г. Япония под давлением американского флота вынуждена была подписать неравный мирный договор с США, который положил конец политике самоизоляции страны. За этим договором последовали аналогичные неравноправные, ущемляющие интересы Японии торговые договоры с европейскими странами (Британией, Францией, Россией и Нидерландами), в результате которых иностранцы приобретали право не только ведения торговли, но и проживания в Японии $[1$, с. 16$]$.
Чтобы избежать участи других азиатских стран, которые были колонизированы западными державами, и сохранить свою независимость, Япония вступила на путь реформ (подробнее см.: [1; 4]).

Несмотря на существовавшие издавна в Японии порты в городах Нагасаки и Хакодатэ, правительство Японии построило новый порт, куда могли бы заходить крупные иностранные суда, в бухте, где располагалась небольшая деревня Иокогама недалеко от Эдо [4, с. 80]. В 1872 г. было открыто железнодорожное сообщение между Токио и Иокогамой $[4$, с. 271]. В скором времени сюда начали стекаться товары со всей Японии, предназначенные на экспорт. Основу экспорта составляли прежде всего сырьевые товары, в первую очередь шелк-сырец и чай $[1$, с. 67].

В середине XIX в. мировыми лидерами по производству шелка уже длительное время были Италия и Китай [14, p. 35]. Но вскоре японский шелк получил всемирное признание благодаря тому, что его качество не уступало ведущим производителям шелка, а цена была вдвое ниже [13, p. 134]. Во многом Япония смогла этого достичь за счет адаптации технических инноваций, заимствованных с Запада, к местным условиям и дальнейшего их усовершенствования $[1$, с. 100 ; 17, с. 341]. Однако у японцев в силу длительной изоляции страны не было необходимых знаний и опыта для работы на мировых рынках, и поэтому они нуждались в иностранных посредниках [1, с. 67].

К тому времени большая часть Индии оказалась под контролем Британской Ост-Индской компании, которая стремилась также расширить свою зону влияния на Дальнем Востоке. И индийские купцы, поощряемые британским правительством, начали приезжать в Японию для ведения бизнеса. В основном они приезжали в Японию из портовых городов Ки- 


\section{ВСЕОБЩАЯ ИСТОРИЯ}

тая, где с 1880-х гг. успешно осуществляли торговлю шелком [18, p. 147].

Первые сведения о численности индийцев в Японии относятся к началу 70-х гг. XIX века. Однако регулярный учет иностранцев и предоставление подробных данных о них в Японии начинается с 1899 г., когда была введена система регистрации иностранцев [5, c. 4]. Также ценным источником могут стать земельные переписи, где уже за 80-е гг. XIX в. можно найти индийские имена Хассан Хирди или М. Мусабои, за которыми закреплено право пожизненного владения земельными участками на территории префектуры Хёго [2, c. 24].

Надо отметить, что большинство индийских фирм, занимавшихся торговлей текстилем в то время, представляли собой семейные предприятия, конкурирующие друг с другом, но вместе с тем сохраняющие сильные традиции родства и земляческую солидарность. Они редко отказывались от родных корней, несмотря на то что участвовали в международной торговле с конца XVIII века. В конце XIX в. движение по созданию акционерных обществ не затрагивало большинство индийских торговцев текстилем и его производителей. Они сохраняли свою индивидуальную идентификацию, поэтому можно предположить, что их капитал часто был довольно ограниченным [12, p. 203].

Для ведения торговли в Японию приезжали представители различных индийских торговых общин: гуджаратцы (парсы, бохра), сикхи, но купцы-синдхи постепенно начали составлять большинство среди прибывавших в страну индийцев $[19$, p. 27]. Таким образом, торговая сеть синдхов была наиболее важной южноазиатской сетью для Японии.

Синдхи - это этническая группа, до 1947 г. проживавшая на территории провинции Синд (с 1843-1947 гг. - северо-западная провинция Британской Индии, а сейчас - территория современного Пакистана), являлись религиозным меньшинством среди мусульманского населения провинции. Большинство синдхов - последователи учения сикхского гуру Нанака и одновременно с этим придерживаются основных догм индуизма [13, p. 4-5]. После раздела Индии и Пакистана в 1947 г. многие из синдхов, исповедующих индуизм, вынуждены были покинуть исламский Пакистан, и большая часть из них осели в Бомбее.

Тем не менее раньше всех, по-видимому, начали приезжать предприниматели-парсы, вероятно, из Гуджарата и Бомбея. Считается, что предприниматель-парс стал первым натурализовавшимся в Японии индийцем [11, c. 116]. Индийский исследователь, писатель М. Уильямс, долгое время проживший в Японии, не обнародуя, правда, своих источников, пишет, что после принятия гражданства этот предприниматель взял себе имя «Кумадзава Импурэсу», в котором соединил фамилию владельца японской фирмы, в которой он работал, а также название корабля, на котором он прибыл в Японию «Empress Queen Victoria» («Empress» в японском прочтении будет «Импурэсу»). О нем также известно, что он женился на дочери своего бывшего работодателя. В дальнейшем Кумадзава основал свою собственную фирму [20]. А в начале эпохи Сёва (около 30-х гг. ХХ в.) он вышел на пенсию, и спокойно провел остаток своих дней в районе Сёнан (рядом с Иокогамой) [11, с. 116].

Большинство индийцев были заняты торговлей шелком, однако предприниматели-парсы также ввозили в Японию краску индиго, овечьи шкуры, циновки и др. [19, p. 28]. Предприниматели-синдхи активно занимались экспортом японских антикварных и ремесленных товаров, сделав их вторым основным после шелка предметом своего бизнеса [13, p. 135]. Мода на товары японского происхождения особенно распространилась по всему миру после участия Японии в Международных выставках, проводившихся в период с 1862 по 1893 год. Массовое увлечение японским искусством нашло отражение в западной культуре того времени и было привилегией не только высшего общества и деятелей искусства, но и среднего класса $[18$, p. 118]. Таким образом, можно предположить, что спрос на ремесленные и сувенирные товары из Японии был очень высок.

Первыми синдхскими фирмами, открывшимися в Японии, были «Вассиамал Ассомул и $\mathrm{K}^{0}{ }_{\text {》 }}$ (Wassiamall Assomull \& Co), которая открыла офис в Иокогаме в 1882 г., «К.А.Дж. Четтирмал и $\mathrm{K}^{\circ}$ 》 (Chotirmall \& Co. Ltd.), Пухумул и братья (Pohoomull Bros) и другие крупные синдхские фирмы, имевшие к тому времени филиалы по всему миру, а их головные офисы, 
как правило, находились в г. Хайдерабад (Синд) [11, с. 131].

Первоначально индийцы селились в Иокогаме, а именно в округе Ямасита-тё, находившейся неподалеку от порта. Причиной этого является то, что Иокогама до 1920-х гг. была главным центром торговли шелком в Японии. Из другого города-порта Японии, Кобэ, экспортировался, главным образом, шелк более высокого качества, тогда как Иокогама специализировалась по более грубым его разновидностям. Именно такой шелк в большей степени интересовал индийских предпринимателей [18, р. 146].

Кроме того, индийцы предпочли именно Иокогаму, потому что конкуренция здесь была ниже, чем в Кобэ, где вся торговля находилась под контролем японских фирм. По различным причинам ни китайцы, ни американцы, проживающие в Иокогаме, не были активно вовлечены в шелковую торговлю, и у индийцев практически не было конкурентов. Индийские купцы считали Иокогаму базой, с которой они в дальнейшем смогут проникнуть на весь японский рынок [7, с. 62-63]. Исследователь Х. Симидзу также делает заключение, что по крайней мере до Первой мировой войны индийские и китайские предприниматели контролировали торговлю Японии с азиатскими странами [19, р. 26].

Международная торговля развивалась активно, и к 1918 г. в Иокогаме насчитывалось уже более 60 фирм (в фирме, как правило, было 2 индийских сотрудника и по крайней мере 1 управляющий-японец [9; 18, p. 147]) [7, c. 62]. Еще в начале 1900-х гг. в Токио был основан клуб «Hindustan Association» («Общество Хиндустана»), а в Кобэ - «Oriental Young men’s club» («Клуб молодых восточных мужчин») [16, p. 13]. А для защиты своих интересов в Японии, так же как и во многих других странах, в 1921 г. синдхскими предпринимателями была создана «Ассоциация индийских коммерсантов г. Иокогама» («Yokohama Merchants Association») [18, p. 146].

\section{Второй этап.}

\section{Формирование общины в Кобэ}

В то же время индийское присутствие в другом городе-порте Японии, Кобэ, также про- должало постепенно увеличиваться (в 1905 г. насчитывалось 59 чел., 1916 - 93, 1921 - 175) $[2$, с. 24]. Большинство индийцев были зарегистрированы под статусом «предприниматели», «наемный рабочий», при этом в основном это были мужчины [5, с. 6].

Социальная жизнь индийцев в Кобэ так же как и в Иокогаме формировалась вокруг основанных ими клубов (система клубов, повидимому, была унаследована ими от колониальной Англии): в 1904 г. в Кобэ был построен «Восточный клуб» («Oriental club»), который был переименован в 1913 г. в «Индийский клуб», а в 1923 г. в Кобэ открылся также «Parsee club» («Клуб парсов») (по-видимому, был переведен из Иокогамы) [5, с. 6]. В клубы, как правило, могли вступить только руководители фирм. Наемные рабочие не могли становиться их членами, что связано со строгой кастовой иерархией, принятой в индийском обществе [2, с. 32].

Большинство индийцев в Кобэ в отличие от индийцев в Иокогаме были заняты импортом хлопка, в котором развивающаяся японская экономика очень сильно нуждалась. В 1891 г. индийская компания «Тата» открыла филиал в Кобэ, а чуть позже, в 1893 г., японская почтовая компания совместно с «Тата» организовала морской рейс из Кобэ в Бомбей, главным образом для доставки индийского хлопка в Японию [6, с. 29-30]. Начавшийся в Японии экономический бум требовал большого количества хлопка, и по объемам его импорта Япония заняла третье место в мире после Англии и Германии.

В конце эпохи Мэйдзи и начале эпохи Тайсё (1912-1915 гг.) 60 \% ввозимого в Японию хлопка было из Индии, а на долю Китая и Америки приходилось 20 \% импортируемого хлопка [10, с. 18]. В 1916 г. в денежном значении экспорт хлопкового текстиля превысил экспорт шелка [5, с. 5]. В 1933 г. были также заключены торговые соглашения между Японией и Индией об обмене хлопкового сырья на готовую продукцию из хлопка [10, с. 19].

1 сентября 1923 г. всего за несколько минут Иокогама, которая находилась вблизи от эпицентра землетрясения, была практически полностью разрушена. Начавшиеся повсюду пожары уничтожили почти все здания индийских фирм. Погибли 23 индийца (их имена 


\section{ВСЕОБЩАЯ ИСТОРИЯ}

не сохранились в истории) из 170, находившихся тогда в Иокогаме. В память о своих погибших соотечественниках и в знак своего соболезнования Японии в 1939 г. «Индийским обществом» в парке Ямасита в центре Иокогамы, на берегу моря, был возведен павильон Мидзуномидай, выдержанный в стиле индийской мусульманской архитектуры [7, с. 63]. У павильона была установлена мемориальная доска с надписью: «С благодарностью от индийских предпринимателей за предоставление помощи во время бедствия». Фонтан до сих пор находится на своем месте в парке Иокогамы, являясь напоминанием о тех страшных событиях, служа символом дружбы между Индией и Японией. Каждый год в день годовщины землетрясения члены индийской общины, включая до сих пор проживающих в Японии потомков предпринимателей-пионеров, проводят перед мемориалом поминальную службу [9].

Потеряв все, что у них было, индийцы бежали из Иокогамы в Кобэ. Там они нашли прибежище у членов местной индийской общины, которая их очень тепло встретила, разместив на какое-то время в индийских клубах. Кроме того, потерявшие все индийцы получали материальную помощь от Британского консульства в Кобэ [2, с. 29].

Городские власти Иокогамы стремились как можно скорее вернуть индийцев, создав при этом условия для их возвращения. Но большей части индийцев понравился Кобэ. У Кобэ был ряд преимуществ по сравнению с Иокогамой. Во-первых, торговые интересы индийцев к тому времени к искусственному (вискозному) шелку. А Кобэ находился ближе к местам его производства, префектуры Фукуи и Канадзава, и был связан с ними прямой веткой железнодорожного сообщения. Соответственно стоимость пересылки, хранения на складе, страховые взносы по сравнению с Иокогамой были гораздо ниже. По этим причинам Кобэ очень быстро превратился в центр шелковой торговли. Уже в 1923 г. экспорт из Кобэ увеличился в 4 раза (60 \% экспорта приходилось на Иокогама, $40 \%$ - Кобэ). А в 1924 г. экспорт шелка из Кобэ составил уже $92 \%$ от всего экспорта из Японии [2, с. 28].

В то же время городские власти Иокогамы не оставляли попыток переманить ин- дийцев из Кобэ в Иокогаму. Борьба двух городов за индийских предпринимателей вполне понятна, учитывая, что на долю индийцев приходилось 70-80 \% всего экспорта окрашенного шелка из Японии [2, с. 29].

Покинув Иокогаму, индийцы рассматривали Кобэ как временное пристанище и не планировали оставаться здесь надолго, тем не менее обратно вернулась лишь треть индийских предпринимателей (лишь 16 фирм из 50) $[5$, c. 6$]$.

Таким образом, если до землетрясения в Японии было два независимых друг от друга центра, через которые осуществлялась торговля, то после землетрясения центр индийской общины уже надолго, до середины 80-х гг. $\mathrm{XX}$ в., переместился в Кобэ. Индийцы, приезжавшие в Японию после 1925 г., уже предпочитали открывать филиалы в Кобэ, а не Иокогама. Кроме того, землетрясение объединило и сблизило индийцев, тем самым сделав их общину сильнее. Число индийских компаний увеличилось со 120-130 компаний в 1925 г. до 163 в 1937 г. и до 200 - в 1939 г., которые составили серьезную конкуренцию местным предпринимателям [5, с. 6]. Спустя некоторое время после землетрясения, индийские фирмы составляли 70 \% всех иностранных фирм в Кобэ [2, с. 28].

Зависимость японских предпринимателей от индийской предпринимательской сети продолжалась на протяжении всех 30-х гг. $\mathrm{XX}$ века. Особенно это было видно на примере торговли текстилем в Сингапуре, где был введен запрет на ввоз японских товаров. Однако японский текстиль ввозился в Сингапур благодаря индийцам, которые его успешно реализовывали, скрывая страну происхождения товара [12, p. 210].

Х. Симидзу отмечает, что большинство индийских предпринимателей в Сингапуре покупали японские товары через посредничество индийцев в Японии, и также они через многочисленные связи с индийцами по всему миру помогали продвигать японские товары в странах Ближнего Востока $[19$, p. 36].

В 1937 г. индийское население в Кобэ достигло пика численности до начала войны и составляло примерно 1000 чел. (674 чел. - согласно данным официальной статистики [2, с. 23]). 
Из справочника «Торговой и промышленной палаты г. Кобэ» за 1928 г. видно, что хотя большинство фирм продолжают заниматься торговлей текстилем, в числе экспортируемых товаров появляются галантерейные товары, камфора, спички, игрушки и даже велосипеды [19, p. 33-34].

Интересным представляется факт, что в наше время знаменитые во всем мире своим высоким качеством японские товары, в довоенное время далеко такими не являлись. $\Gamma$-н Сатояма, в то время тесно сотрудничавший с индийцами, отмечает, что в его практике постоянно случались курьезы с товарами, предназначенными на экспорт: «Карандаши часто были без стержня, рубашки с приклеенными, а не пришитыми пуговицами, носки без пары. Это часто служило предметом конфликтов и подрывало взаимное доверие между индийцами и японцами» [6, с. 68].

Так как большинство индийских предпринимателей в Японии составляли синдхи, чьи имена очень часто имеют окончания «мал» или «чанд», то японцы всех индийцев в Кобэ стали звать в соответствии с японской фонетикой «мару». Индийцы предпочитали селиться рядом друг с другом. Так, к югу от центра Кобэ, района Санномия, на улицах Исогами-доори, Хатиман-доори и на Исобэ-доори, проживало более 130 индийцев, и эти окрестности в народеполучили неофициальное название «Бомбейтаун» $[19$, р. 25]. Здесь индийцы селились в двухэтажных зданиях, на первом этаже индийцы работали, а на втором этаже располагались жилые помещения [9].

В основанный еще в 1904 г. в Кобэ «Oriental club» («Восточный клуб») входили практически все индийцы в Японии, однако в начале 1930-х гг. предприниматели-синдхи решают создать свой собственный клуб «Silk Merchant Association» («Ассоциация торговцев шелком»), наследницей его после войны стало «Indian Social Society» («Индийское социальное общество»). Причиной, вероятно, были различия в образе жизни: синдхи не были в большинстве своем вегетарианцами, и у них не было строгого запрета на алкоголь, в отличие от других индийцев [9].

К. Марковиц также отмечает, что в целом предприниматели-синдхи за рубежом были довольно замкнутой общиной, предпочитали об- щаться преимущественно друг с другом и не завязывали близких отношений с представителями других южноазиатских общин [18, p. 183]. Однако несмотря на это, различные индийские общины не враждовали друг с другом и даже регулярно проводили совместные матчи по бильярду, крикету и выступали объединенной спортивной командой против других иностранных команд, например, англичан или американцев. Образ жизни индийских предпринимателей был достаточно неторопливым, морские рейсы, на которых предприниматели отправляли товары, были не чаще двух раз в месяц. В результате предприниматели много времени проводили в созданных ими клубах, которые стали для них «домом вдали от дома» [9].

Большинство индийских контор в Японии были филиалами фирм, главный офис которых находился в Индии. Индийцы приезжали работать в Японию по двухлетнему или трехлетнему контракту, оставляя свои семьи в Индии. По словам одного из информантов, его отец, один из пионеров-предпринимателей в Японии, периодически ездил в свой родной город Хайдерабад по делам и чтобы навестить семью. В один из таких приездов он женился на девушке, которую ему выбрали родители. Тем не менее жена не последовала сразу за ним в Японию. Сперва они виделись примерно раз в год, когда отец приезжал в Индию. В военные годы и несколько лет после войны отец вовсе не имел возможности приехать в Индию. После разделения Индии и Пакистана мать жила в Лакнау у родственников, воспитывая детей в одиночку. И только после 8 лет разлуки супруги вновь встретились, и тогда мать переехала жить в Японию [9].

В 1935 г. британский парламент принял Закон об Управлении Индией, давший определенные элементы самоуправления провинциям Британской Индии и некоторые свободы индийским подданным британской короны. В этом же году индийцы в Кобэ перед зданием «Индийского клуба» на флагштоке впервые подняли индийский трехцветный флаг с изображением прялки в центре, который был ранее утвержден партией «Индийский национальный конгресс» [10, с. 23]. В этом акте можно также увидеть оппозиционные настроения по отношению к колониальному правлению Великобритании. 


\section{ВСЕОБЩАЯ ИСТОРИЯ}

Индийская община продолжала укреплять свои позиции в Японии. В 1937 г. в Кобэ была образована «Индийская торговая палата» («The Indian Chamber of Commerce») [5, c. 6]. Данная организация стремилась объединить всех индийских предпринимателей, вне зависимости от их религии и касты.

В Японии индийским фирмам в основном приходилось нанимать на службу японских работников, а штат индийских сотрудников, как было показано выше, обычно ограничивался одним работником и управляющим. Это и объясняет причину того, что индийская община в Японии была довольно малочисленной, и это не соответствовало истинному значению Японии в развитии торговой сети и ее вкладу в мировой товарооборот [18, p. 147]. К. Марковиц также подчеркивает, что обычно в странах, являющихся источником для оптовых закупок (Япония, Китай), предпринимателей-синдхов всегда было меньше (не более 10 \% людских ресурсов сети), чем в регионах, где велась розничная торговля (например, на Филиппинах, в Сингапуре, Египте и т. д.) [18, p. 235].

Несмотря на свою малочисленность, индийские предприниматели смогли установить тесные связи с японскими поставщиками, а благодаря налаженной предпринимательской сети продавать японские товары по всему миру.

В период Второй мировой войны большинство индийских предпринимателей вынуждены были покинуть Японию. Однако многие из них вернулись после окончания войны по специальному приглашению японского правительства и оккупационных властей и селились преимушественно в Кобэ. Дальнейшая миграция вплоть до конца 80-х гг. XX в. была тесно связана с довоенным этапом [19, p. 44] и имела преимущественно цепной характер, свойственный индийской этнической миграции по всему миру (подробнее см.: [3; 8]).

Таким образом, рассмотрев два первых этапа формирования индийской общины в довоенные годы, можно заключить, что несмотря на свою малочисленность в этот исторический период, индийская предпринимательская сеть с центром в Японии внесла большой вклад в развитие японской экономики. Индийцы в Кобэ и Иокогаме благодаря крепким земляческим связям и этнической солидарности сумели создать для себя здесь комфор- тную среду обитания, а Кобэ и в наши дни продолжает являться центром концентрации индийской предпринимательской общины, основа которой была сформирована еще до начала Второй мировой войны.

\section{СПИСОК ЛИТЕРАТУРЫ}

1. История Японии. В 2 т. Т. 2 : 1868-1998 / отв. ред. А. Е. Жуков. - М. : Ин-т Востоковедения РАН, 1998. $-703 \mathrm{c}$.

2. Каная Кумао Кобэ то индодзин (Кобэ и индийцы) // Нитиинбункатокусю : (Особый выпуск по культуре Индии и Японии) II. - 1964. - С. 22-33.

3. Котин, И. Ю. Побеги баньяна: Миграция населения из Индии и формирование узлов южноазиатской диаспоры / И. Ю. Котин. - СПб. : Петербургское Востоковедение, 2003. - 265 с.

4. Мещеряков, А. Н. Император Мэйдзи и его Япония / А. Н. Мещеряков. - М. : Наталис, 2009. -735 с.

5. Минамино, Такэси, Сава Мунэнори Дзайнити индодзин сякай но хэнсэн - Тэйдзюти Кобэ дзицурэй тоситэ (Изменения индийской общины в Японии на примере индийской общины в Кобэ) // Хёго тири (География Хёго). - 2005. - № 50. - С. 4-15.

6. Мисуми, Саитиро Кайсо: но нитиинканкэй (История индо-японских отношений). - То:кё: То:кё: гайкокуго дайгаку тикю: сякай сэнтан кё:ику сэнта:, 2008. -163 c.

7. Томинага Тидзуко Индодзин имин сякай но рэкиси то гэндзё: Ёкохама, Кобэ, Окинава (История и настоящее индийской общины в Иокогаме, Токио, Кобэ и Окинава) // Нитиин бунка (Культура Индии и Японии). - 1994. - С. 58-95.

8. Томинага Тидзуко Индодзин имин сякай но рэкиси то гэндзё: Ёкохама, Кобэ, Окинава (дзоку) (История и настоящее индийской общины в Иокогаме, Токио, Кобэ и Окинава (продолжение) // Нитиин бунка (Культура Индии и Японии). - 1999. - С. 52-79.

9. Фирсова, В. С. Индийская диаспора в Японии. Материалы полевых исследований в Японии с 9.2011-9.2012 гг. / В. С. Фирсова // Архив МАЭ РАН. - Шифр: К. І. - Оп. 2. - № 2252.

10. Фудзита Сэйнусукэ Кобэ о тю:син суру нитиин кэйдзай ко:рю: то дзайрю: индодзин но до:ко : (Индо-японские отношения в области экономики на примере Кобэ и изменение численности индийцев) // Нитиин бунка (Культура Индии и Японии). 1994. - C. $15-57$.

11. Футами Сэнпэй Ёкохама юсюцу кину гё:си (История экспорта шелка из Иокогамы). - Ёкохама : Ёкохама юсюцу кину гё:си канко:кай, 1958. -682 с.

12. Brown, R. A. Capital and Entrepreneurship in South-East Asia / R. A. Brown. - N. Y. : St. Martin's press. Houndmills : Macmillan press, 1994. -302 p. 
13. Falzon, M. A. Cosmopolitan Connections: The Sindhi diaspora, 1860-2000 / M. A. Falzon. - Leiden : Brill Academic Pub., 2000. - 294 p.

14. Federico G. An economic history of the silk industry, 1830-1930 / G. Federico. - Cambridge : Cambridge University Press, 1997. - 259 p.

15. Kotkin, J. Tribes: how Race, Religion and Identity determine success in the New Global Economy / J. Kotkin. - N. Y. : Random house, 1994. -343 p.

16. Kumar, M. S. Trade of the Times: Reconceiving "Diaspora" with the Sindhi Merchants in Japan. A Thesis for the degree of Master of social science / M. S. Kumar. - Singapore, 2010. -213 p.

17. Ma, D. The modern silk road: The global rawsilk market, 1850-1930 / D. Ma // The Journal of economic history. - 1996. - Vol. 56, № 2. - P. 330-355.

18. Markovits, C. The Global World of Indian Merchants, 1750-1947: Traders of Sind from Bukhara to Panama / C. Markovits. - Cambridge : Cambridge University Press, 2005. -327 p.

19. Shimizu, H. The Indian merchants of Kobe and Japan's trade expansion into Southeast Asia before the Asian-Pacific War / H. Shimizu // Japan Forum. 2005. - Vol. 17, № 1. - P. 25-48.

20. Williams, M. Japan-India Connections through the ages / M. Williams. - Electronic text data. -Mode of access: http://williamszemi.blogspot.ru/search?q=indian+in+japan (date of access: 25.02.2016). - Title from screen.

\section{REFERENCES}

1. Zhukov A.E., ed. Istoriya Yaponii. V 2 t. T. 2 : 1868-1998 [History of Japan. In 2 vols. Vol. 2]. Moscow, Institut Vostokovedeniya RAN, 1998. 703 p.

2. Kanaya Kumao. Kobe to indojin [Kobe and Indians]. Nichiin bunka [Japanese and Indian Culture], 1964, vol. 2, pp. 22-33.

3. Kotin I.Yu. Pobegi banyana: Migratsiya naseleniya iz Indii i formirovanie uzlov yuzhnoaziatskoy diaspory [The Banyan Shoots: Emigration from India and the Formation of the "Nodes" of the South Asian Diaspora]. Saint Petersburg, Peterburgskoe Vostokovedenie Publ., 2003. 265 p.

4. Meshcheryakov A.N. Imperator Meydzi i ego Yaponia [Emperor Meiji and His Japan]. Moscow, Natalis Publ., 2009. 735 p.

5. Minamino Takeshi, Sawa Munenori. Zainichi indojinn shakai no hensei. Teiju:chi Kobe jitsurei toshite [Changes of Indian Community in Japan. Using the Example of Indian Community in Kobe]. Hyogo chiri [Geography of Hyogo Prefecture], 2005, no. 50, pp. 4-15.

6. Misumi Saichiro. Kaisouno nichiin kankei [The History of Indo-Japanese Relations]. Tokyo, Tokyo gaikokugo daigaku chikyu: shakai sentan kyoiku senta, 2008. 163 p.
7. Tominaga Chizuko. Indojin imin shakai no rekishi to genjou: Yokohama, Kobe, Okinawa [The Past and the Present of Indian Community: Yokohama, Kobe, and Okinawa]. Nichiin bunka [Japanese and Indian Culture], 1994, pp. 58-95.

8. Tominaga Chizuko. Indojin imin shakai no rekishi to genjou: Yokohama, Kobe, Okinawa [The Past and the Present of Indian Community: Yokohama, Kobe, and Okinawa. Part II]. Nichiin bunka [Japanese and Indian Culture], 1999, pp. 52-79.

9. Firsova V.S. Indiyskaya diaspora v Yaponii. Materialy polevykh issledovaniy v Yaponii s 9.20119.2012 gg. [Indian Diaspora in Japan. Field-Work Materials in Japan From 9.2011 to 9.2012]. Arkhiv MAE $R A N$, K. I, Op. 2, no. 2252.

10. Fujita Seinusuke. Kobe o chushin suru nichiin Keizai kouryu to zairyuu indojin no doukou [Indo-Japanese Relations in the Economy and Dynamic of Indian Population Growth in Kobe]. Nichiin bunka [Japanese and Indian Culture], 1994, pp. 15-57.

11. Futami Senpei. Yokohama yushutsu kinu gyoushi [History of Silk Export Enterprises in Yokohama]. Yokohama, Yokohama yushutsu kinu gyoushi kankoukai, 1958. $682 \mathrm{p}$.

12. Brown R.A. Capital and Entrepreneurship in South-East Asia. New York, St. Martin's Press; Houndmills, Macmillan Press, 1994. 302 p.

13. Falzon M.A. Cosmopolitan Connections: The Sindhi diaspora, 1860-2000. Leiden, Brill Academic Publ., 2000. 294 p.

14. Federico G. An Economic History of the Silk Industry, 1830-1930. Cambridge, Cambridge University Press, 1997. 259 p.

15. Kotkin J. Tribes: How Race, Religion and Identity Determine Success in the New Global Economy. New York, Random house, 1994. 343 p.

16. Kumar M.S. Trade of the Times: Reconceiving "Diaspora" with the Sindhi Merchants in Japan. A Thesis for the Degree of Master of Social Sciences. Singapore, 2010. $213 \mathrm{p}$.

17. Ma D. The Modern Silk Road: The Global Raw-Silk Market, 1850-1930. The Journal of Economic History, 1996, vol. 56, no. 2, pp. 330-355.

18. Markovits C. The Global World of Indian Merchants, 1750-1947: Traders of Sind from Bukhara to Panama. Cambridge, Cambridge University Press, 2005. $344 \mathrm{p}$.

19. Shimizu H. The Indian Merchants of Kobe and Japan's Trade Expansion Into Southeast Asia Before the Asian-Pacific War. Japan Forum, 2005, vol. 17, no. 1, pp. $25-48$.

20. Williams M. Japan-India Connections through the Ages. Available at: http://williamszemi. blogspot.ru/search?q=indian $+\mathrm{in}+\mathrm{japan}$ (accessed February 25, 2016). 